\begin{tabular}{c} 
International Journal of Engineering \& Technology, $7(4.5)(2018) 556-559$ \\
SPC \\
Website $: \frac{w w \text {. sciencepubco.com/index.php/IJET }}{\text { Research paper }}$ \\
\hline
\end{tabular}

\title{
Cloud based agricultural field parameters monitoring using ESP8266 and ZigBee
}

\author{
Rohit Samkaria $^{1}{ }^{*}$, Rajesh Singh $^{1}$, Anita Gehlot ${ }^{1}$, Sushabhan Choudhary ${ }^{1}$ \\ ${ }^{1}$ Department of Electronics Instrumentation and Control Engineering University of Petroleum and Energy Studied, Dehradun, India \\ *Corresponding author E-mail: rohit.samkaria93@gmail.com
}

\begin{abstract}
To improve the production of agricultural, monitoring of the different parameters in the field has been proven to be the powerful tool. With the advent of technology crop monitoring may be achieved at very precise level; however Wireless Sensor Area Network result in low power and low cost deployments and Cloud based field monitoring is becoming a dominant option. So a method has been developed for agricultural systems that act as phonological indicators of various seasonal developments in the field and number of climate effect upon the regional growth over the crop for a broad region using (IoT) Internet of Things. The developed platform has been evaluated for various field parameters, creating a WSAN with a base station to record various parameters and finally uploaded this parameter to the Internet server. The performance result of the developed system has shown the feasibility and confirms its future aspects in broad sense.
\end{abstract}

Keywords: IOT; WSN; ZigBee; Cloud Computing

\section{Introduction}

As Internet of Things (IoT) is the essential foundation to acknowledge urban detecting, it ought to be adaptable to bolster different application prerequisites and helpful administration of framework. Motivated by software-characterized organizing, which expects to make arranges more adaptable [90]. There is another precision agriculture management system (PAMS) in light of Internet of Things (IoT) and WebGIS. It utilizes module recon- ciliation technique and open source software can help us to de-crease the advancement cost and to enhance the system effective- ness [1]. Significant test in Agriculture is to develop create in the homestead and convey it to the end shoppers with the most ideal cost and most ideal quality. As of now everywhere throughout the world, it is found that around half for the homestead create never achieve the end customer because of wastage and problematic costs [2]. Since the IoT (Internet of Things) innovation was con- nected to horticulture, the modernization and the data innovation of agribusiness have been enormously made strides. There is an idea of IoT and outlines applications in the cutting edge rearing, trim development, quality and security of agrarian items checking to concentrate on RFID innovation The Integrated monitoring system monitoring system monitor all the parameters. [3]. It con- centrates on system framework, which is the establishment for IoT usage [4]. As of late, greenhouse innovation in farming is to mechanization, data innovation bearing with the IoT (Internet of things) innovation fast improvement and wide application [6]. In view of significant components of cloud computing and key strat- egies of internet of things, cloud computing, representation and SOA innovations can fabricate huge information required in rural creation. Cloud computing is firmly identified with internet of things. A flawless mix of them can advance quick improvement of agrarian modernization, acknowledge keen agribusiness and viably unravel the issues concerning horticulture, field and ranchers
IoT is firmly identified with distributed computing in a way that IoT acquires effective processing instruments through distributed computing and distributed computing finds the best honing chan- nel in view of IoT [7]. Agrarian data cloud is built in view of dis- tributed computing and keen horticulture is developed with blend of IoT and RFID. Equipment assets in horticultural data system are coordinated into asset pool by utilizing vitalization innovation, accomplishing dynamic conveyance of asset and adjust of load, fundamentally enhance proficiency of asset utilizing. The com- plexity of the WSAN deployed towards the complex network system and optimize design required several constraints [8]. Sub- stantial measure of information acquired by utilizing radio recur- rence ID, remote correspondence, programmed control, data de- tecting strategies of IoT are dealt with agrarian data cloud, genu- inely acknowledging brilliant agribusiness [9]. The agro ecologi- cal condition control subsystem incorporates:

1) Water quality observing, programmed change of water quality

2) Accurate treatment spares compost

3) Monitor soil constituent, soil stickiness, light, wind, air, and so on.

The farming asset control subsystem incorporates:

1) Intelligent nursery that permits programmed modification of temperature

2) Water system that can naturally control stream and spare water

3) Scientific ailment and irritation observing [10]. 


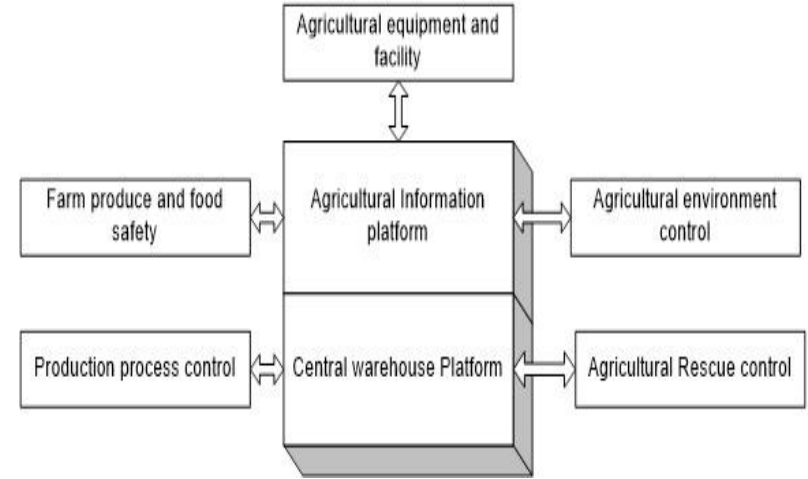

Fig. 1: Data Center Architecture Based on Cloud Network.

Rustic territories in South Africa and Zambia confront various comparative issues in the areas of horticulture, network, water, transport, wellbeing and instruction and so on., which calls for possibly comparative answers for be coordinated towards under- standing these issues [11]. Farming information technology (AIT) has been comprehensively connected to each part of horticulture and has turned into the best means and apparatuses for improving agrarian efficiency and for making utilization of full rural assets [12].

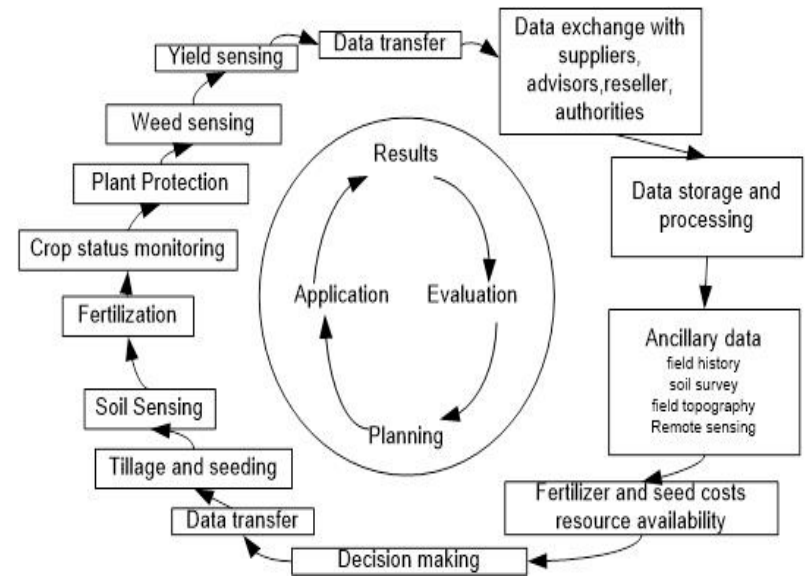

Fig. 2: Exam of Agriculture Information Management Flow in Crop Production.

Our nation is one of the rare water assets in 13 nations on the planet, lack of water assets and in addition the low use of water assets limits our nation economy growing economically. The ex- actness farming water system frameworks in light of the internet of things (IOT) technology, and concentrates on the equipment engineering, arrange design and software prepare control of the accuracy water system framework [13]. In perspective of the com- ponents of present day horticulture and ranch createcoordinations, a SCOR model (Supply-Chain Operations Reference-model) of agrarian items in view of the Internet of things has been advanced through the change of the coordinations model of customary farm- ing items [14].

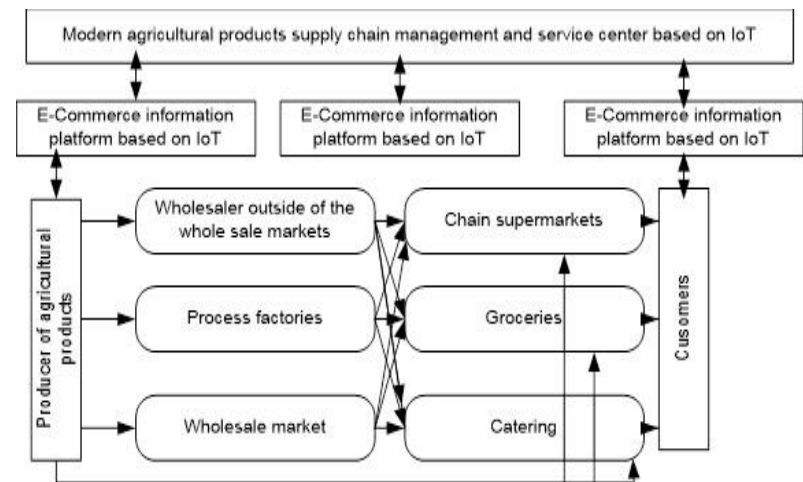

Fig. 3: The Operation Mode for Modern Agricultural Products Supply Chain Logistics Based on IOT.

\section{Proposed system}

The system is developed over the Arduino Uno open source platform. For the agricultural monitoring the different type of sensors which are mainly utilizes for the agricultural parameter are deployed with the Arduino unit which is acting as the controller unit [15]. Now the each node is powered by the battery source and with the zigbee to transmit the data in the surrounding. There are multiple node that having all these agricultural monitoring sensors and deployed with the zigbee to create a network of $n$ number of parameter monitoring nodes. There is a base station that is collect- ing the data of all these wireless nodes. The data is received serial- ly form the transmitter nodes and differentiate at the base station. Finally this data is uploaded to the server through the NodeMCU open source platform and can be access through the webserver or through the mobile aap which is connected to internet.

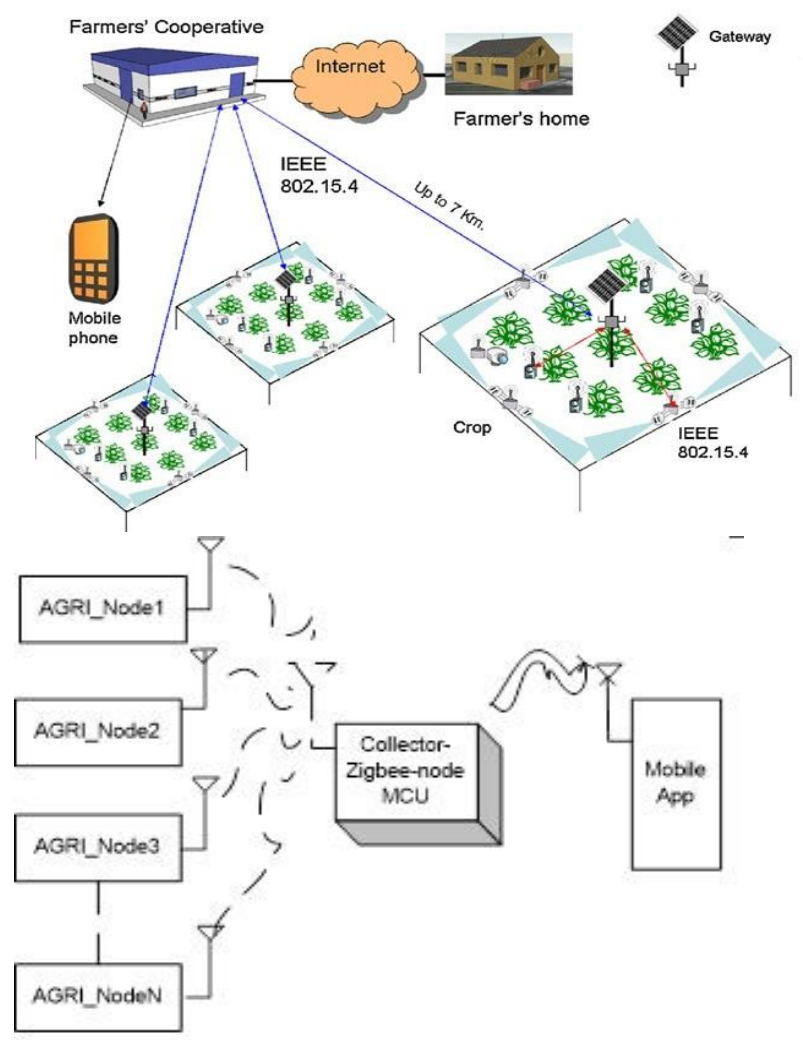

Fig. 4: Schematic Block Diagram of the System.

Figure shows the architecture block diagram of the single node which comprises of different data extraction sensors like Fire Sensor, Water Level Sensor, Soil Moisture Sensor, Temperature and Humidity Sensors in which few are digital sensor and other are analog sensor. The status of digital sensor can be read directly over the digital pin of the Arduino Uno but for the analog sensors the output of the sensors is read through the ADC of the controller which finally provide the digital levels corresponds to the output of the sensor and these digital levels need to be calibrated with the data provided in the data sheet of the defined sensor. After data extraction, controller unit stored these data in the internal memory of the controller and retain this data until it transmit to base station through serially USART of the controller. This process is put upon the continuous loop, so sensors provide there data, controller extract it and through this data to base station serially 


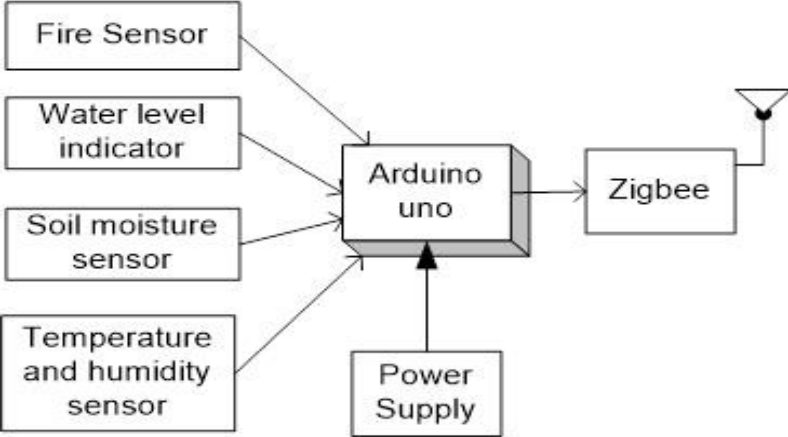

Fig. 5: Architecture of One Node Using Zigbee.

Fig. 5 shows the architecture block diagram of the receiving node and cloud uploading of the data. In the receiving side the data is received serially through the USART of the controller. The controller needs to be a algorithm which could capable to differentiate the data of different nodes. After differentiating the data, controller stored this data on the external memory connected with the controller and then this data is extracted by the NodeMCU and finally uploaded to the cloud server so that it can be access through the webserver or through the mobile aap.

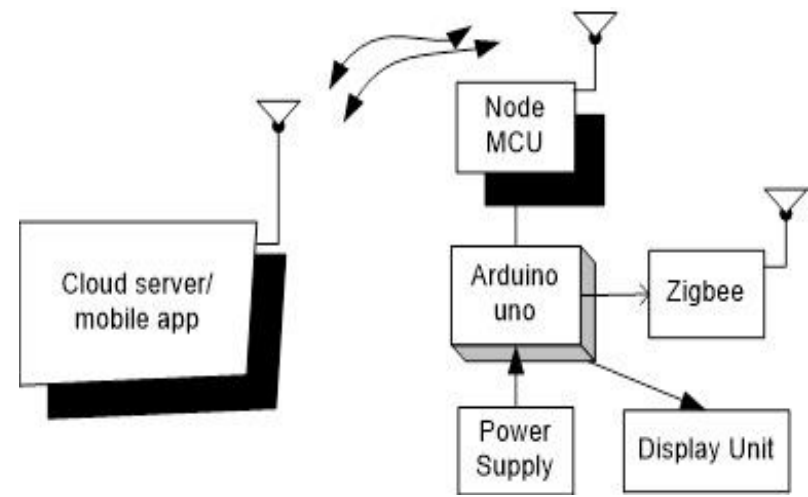

Fig. 6: Architecture of Collector-ZigBee-Node MCU and Cloud Server/Mobile App.

\section{Hardware development}

The software development part consists of virtually simulation of the system over the Proteus simulation. Various virtually components placed over the workspace of the simulator and interconnected with the each other. The program is developed over the open source Arduino platform as the hex file generate after suc- cessfully execution the code is dumped into the simulation to check the results.

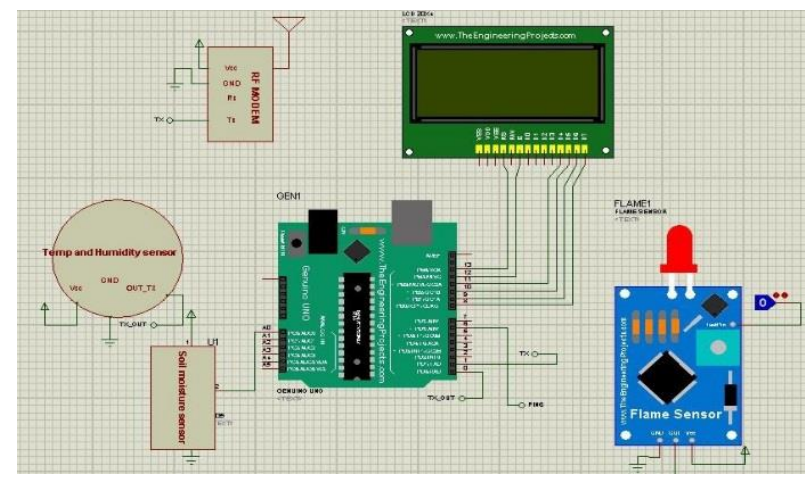

Fig. 7: Proteus Model of One Sensor Node in Agricultural Field.

The fig. 7 shows the Proteus simulation model of the one node in which various virtual sensors are connected with the controller, data is displayed over the LCD (Liquid Crystal Display), and the data transmit through the zigbee.

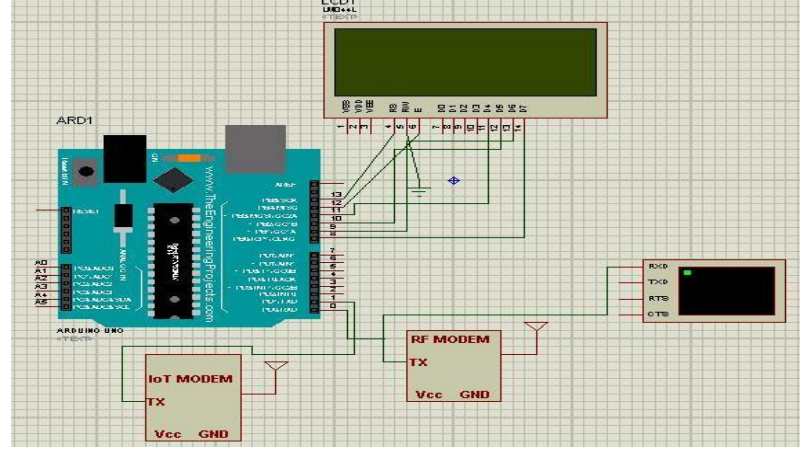

Fig. 8: Proteus Model of Collector-Zigbee-Node MCU and Cloud Server/Mobile App.

Fig 8 shows the Proteus simulation of the receiving node and the cloud uploading of the data. The data received at the base station through the zigbee and finally this data is uploaded to the cloud.

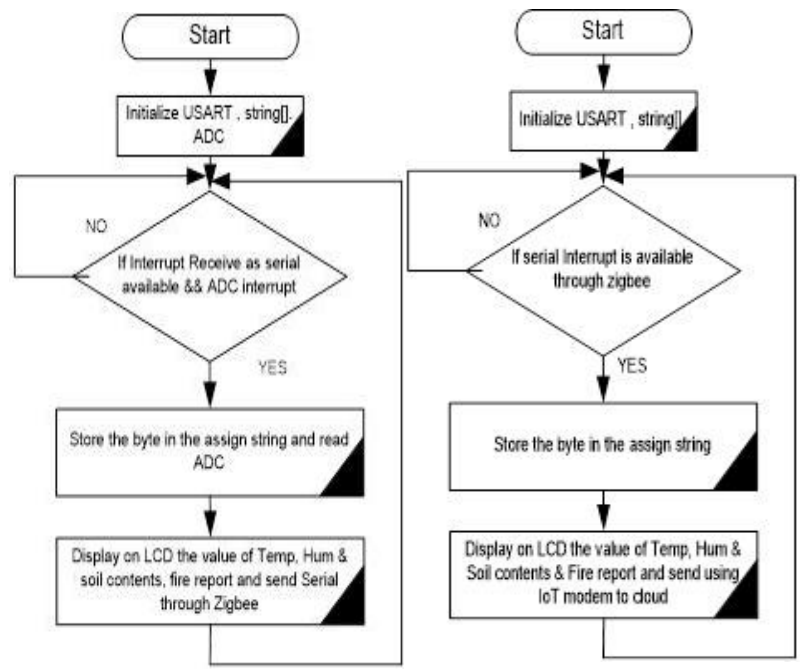

Fig. 9: A) Flow Chart of One Node Using Zigbee B) Flow Chart of Collector- ZigBee-Node MCU and Cloud Server/Mobile App.

In the software algorithm, transmitter side USART is initializing and ADC mode is activated. If data is available then store it and display this data over the LCD and transmit through the ZigBee and in the receiving side the USART is initialize and check whether data is available from the transmitting node or not, if available then store this data and upload to the server.

\section{Result}

This paper is for the agricultural parameter monitoring which measure the different field or crop parameters transmit the data to the base station and this data is uploaded to the cloud. The proto- type is developed using open source Arduino platform and NodeMCU. The various parameter, which are measured and up- loaded to the cloud, are helpful for the farmers and the agricultural researchers to monitor various parameter without visiting the field. The system is reliable and provides five different parameters, which are uploaded to the internet.

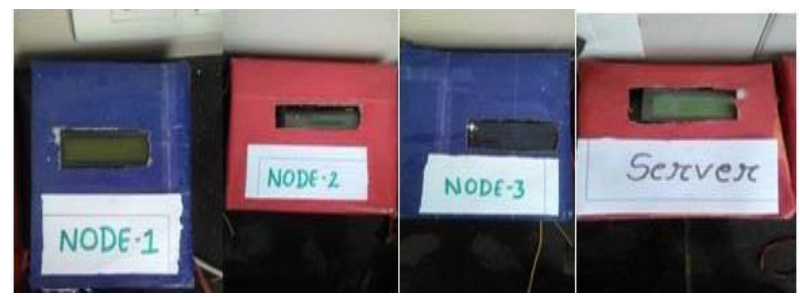

Fig. 9: Snapshot of Developed Nodes. 


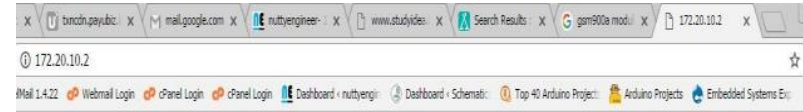

AGRICULTURAL PARANIETER VIONITORING ONLINE PORTAL

$$
\begin{aligned}
& \text { NOOE1 DATA: NOOE2 DATA: NOOES DATA: } \\
& \text { Fre: NOFRE FIRE : NOFRE FRE: NOFRE } \\
& \text { Water Letel: } 4 \mathrm{CM} \text { : Water Lerel: } 5 \mathrm{CM} \text { : Water Level : } 6 \mathrm{CM} \\
& \text { Soll Moisture: } 7 \% \text { Soll Moisture: } 5 \% \text { - Soll Moisture: } 8 \%
\end{aligned}
$$

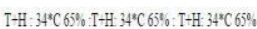

Fig. 10: Screenshot of the Online Portal.

\section{Conclusion and future scope}

The research developed an integrated Wireless Sensor Area Network incorporated with the (IoT) Internet of Things for agri- cultural field or crop monitoring. The overall architecture is an innovative deployment of cloud computing or IoT technology. Therefore our approach is not only to monitor the data at a single base station for singe crop, but also for multiple field parameters scattered at several kilometers area throughout the globe where the internet facilities are available. The work carried out in this paper will help the researchers to know more about the cloud computing and they can implement number of technique by their new ideas.

In the future extension, the cloud base monitoring can be further extended to the decision making capabilities like if farmer re- ceived the soil moisture data in his mobile aap and found that there need to be water the by simply pressing a radio button in is mobile the farer can switch on the water pump in the field.

\section{References}

[1] Ye, Jiuyan, et al. "A precision agriculture management system based on Internet of Things and WebGIS." Geoinformatics (GEOINFORMATICS), 2013 21st International Conference on. IEEE, 2013.

[2] .Patil, V. C., et al. "Internet of things (Iot) and cloud computing for agriculture: An overview." Proceedings of Agro-Informatics and Precision Agriculture (AIPA 2012), India (2012): 292-296.

[3] Al Rasyid, M. Udin Harun, et al. "Pollution Monitoring System Using Gas Sensor Based On Wireless Sensor Network." Inter- national Journal of Engineering and Technology Innovation 6.1 (2016): 79-91.

[4] Shenoy, Jeetendra, and Yogesh Pingle. "IOT in agriculture." Computing for Sustainable Global Development (INDIACom), 2016 3rd International Conference on. IEEE, 2016.

[5] Shifeng, Yao, et al. "Application of IOT in Agriculture [J]." Journal of Agricultural Mechanization Research 7 (2011): 190- 193

[6] Stoces, M., et al. "Internet of Things (IoT) in Agriculture- Selected Aspects." AGRIS on-line Papers in Economics and in- formatics 8.1 (2016): 83.

[7] Zhao, Ji-chun, et al. "The study and application of the IOT technology in agriculture." Computer Science and Information Technology (ICCSIT), 2010 3rd IEEE International Conference on. Vol. 2. IEEE, 2010.

[8] Pau, Giovanni. "Power consumption reduction for wireless sensor networks using a fuzzy approach." International Journal of Engineering and Technology Innovation 6.1 (2016): 55-67.

[9] TongKe, Fan. "Smart agriculture based on cloud computing and IOT." Journal of Convergence Information Technology 8.2 (2013).

[10] Dlodlo, Nomusa, and Josephat Kalezhi. "The internet of things in agriculture for sustainable rural development." Emerging Trends in Networks and Computer Communications (ETNCC), 2015 International Conference on. IEEE, 2015.

[11] Yan-e, Duan. "Design of intelligent agriculture management information system based on IoT." Intelligent Computation Technology and Automation (ICICTA), 2011 International Conference on. Vol. 1. IEEE, 2011.

[12] Li, Sanbo. "Application of the internet of things technology in precision agriculture irrigation systems." Computer Science \& Service System (CSSS), 2012 International Conference on. IEEE, 2012.
[13] Lianguang, Mo. "Study on Supply-Chain of Agricultural Products based on IOT." Measuring Technology and Mechatronics Automation (ICMTMA), 2014 Sixth International Conference on. IEEE, 2014.

[14] Gehlot, Anita, et al. "WPAN and PSO based Water Quality Monitoring with LabVIEW as data logger." International Jour- nal of Engineering and Technology (IJET) 7.5 (2015).

[15] Agarwal, Ateev, et al. "WPAN Based Cattle Health Monitoring With Labview as a Data Logger." International Journal of Fu- ture Generation Communication and Networking 9.6 (2016): 274-284. 